Bond University

Research Repository

\title{
Resilience, alexithymia, and university stress in relation to anxiety and problematic alcohol use among female university students
}

Lyvers, Michael; Holloway, Natalie; Needham, Katarina; Thorberg, Fred A.

\section{Published in:}

Australian Journal of Psychology

DOI:

10.1111/ajpy. 12258

Licence:

Other

Link to output in Bond University research repository.

Recommended citation(APA):

Lyvers, M., Holloway, N., Needham, K., \& Thorberg, F. A. (2020). Resilience, alexithymia, and university stress in relation to anxiety and problematic alcohol use among female university students. Australian Journal of Psychology, 72(1), 59-67. https://doi.org/10.1111/ajpy.12258

\section{General rights}

Copyright and moral rights for the publications made accessible in the public portal are retained by the authors and/or other copyright owners and it is a condition of accessing publications that users recognise and abide by the legal requirements associated with these rights.

For more information, or if you believe that this document breaches copyright, please contact the Bond University research repository coordinator. 
Resilience, Alexithymia, and University Stress in Relation to Anxiety and Problematic Alcohol Use among Female University Students

${ }^{1}$ Michael Lyvers, Ph.D.

${ }^{1}$ Natalie Holloway, Bachelor of Psychological Science (Honours)

${ }^{1}$ Katarina Needham, Bachelor of Psychological Science (Honours)

${ }^{2}$ Fred Arne Thorberg, Ph.D.

${ }^{1}$ School of Psychology, Bond University

Gold Coast Qld Australia

${ }^{2}$ Faculty of Medicine, University of Oslo

Oslo, Norway

Corresponding Author: Michael Lyvers

Email: mlyvers@,bond.edu.au

Phone: +61755952565 
Resilience and University Stress 1

Resilience, Alexithymia, and University Stress in Relation to Anxiety and Problematic Alcohol Use among Female University Students 


\begin{abstract}
Objectives. University students in Australia report higher levels of stress than non-students of the same age, with females reporting higher stress than males. The ability to successfully adapt to, and cope with, stressful situations and events, often referred to as resilience, requires social and interpersonal resources as well as the ability to effectively self-regulate emotions. When such resources and abilities are deficient, responses to university stress are likely to be maladaptive. Deficient emotional self-regulation is characteristic of individuals with the subclinical personality trait alexithymia, who also tend to suffer from social and interpersonal difficulties; thus students with alexithymia may be especially susceptible to university stress and associated adverse outcomes of low resilience. The present study examined resilience in relation to alexithymia, university stress, and two common outcomes of the latter in female university students: anxiety and problematic drinking. Method. Validated self-report measures of the relevant constructs were completed online by 136 female university students from two Australian universities. All participants indicated they had English-language proficiency and no history of serious head injury or diagnosed psychological disorder.

Results. Serial mediation models indicated that resilience showed the predicted protective relationship to both problematic drinking and anxiety through lower levels of alexithymia and university stress. Conclusions. Findings suggest that students who lack resilience are more likely to report stress at university, as well as associated adverse outcomes such as anxiety and problematic drinking, due to deficiencies in emotional self-regulation and inadequate use of social and interpersonal resources for successful coping.
\end{abstract}


In Australia, university students report experiencing stress more frequently than nonstudents of the same age, with female students reporting significantly higher stress than male students (Australian Psychological Society, 2015; Rickwood, Telford, O’Sullivan, Crisp \& Magyar, 2016). Such gender-linked university stress is attributable to the unique combination of stressors often faced by students at university (e.g., see Rickwood et al., Table 3, p. 16). University-related stress can stem from the transition to university life, academic demands, new living arrangements, financial difficulties, meeting new people, and changes in relationships with family, friends and lovers (Hartley, 2011; Pidgeon, Rowe, Stapleton, Magyar, \& Lo, 2014; Stallman \& Hurst, 2016). High levels of stress among students can have detrimental impacts on academic performance, and in some cases may lead to university dropout and/or trigger the onset of an anxiety or other psychological disorder (Carlson \& Voss, 2017; Shi, Liu, Wang \& Wang, 2015).

Resilience refers to the ability to adapt to, and cope with, adverse or stressful events (Williams, Ciarrochi \& Deane, 2010). In the university context, resilience can facilitate the management of academic demands, such as assessment deadlines and examinations, and enhance academic outcomes (Pidgeon, McGrath, Magya, Stapleton \& Lo, 2014). However, resilience requires internal and external resources for successful coping, including effective emotion regulation skills and accessible social support (Li, 2008; Williams et al., 2010; Yoon, Lee, Lee, Cho, \& Lee, 2014). The ability of a student to process and regulate emotions associated with stressful life events, as well as the availability of social support, are likely to be especially important for managing university-related stress. Thus unsurprisingly, students with high levels of alexithymia are reported to be more negatively affected by university stress compared to peers with low or no alexithymia (Kerr, Johnson, Gans, \& Krumrine, 2004). 
Alexithymia is a subclinical personality trait characterized by difficulties in identifying and describing emotional feelings and a literal, utilitarian and externally oriented cognitive style (Sifneos, 1973; Taylor \& Bagby, 2004). The aetiology of alexithymia is unclear. Although much evidence indicates that it is a stable trait in the general population (Hiirola et al., 2017; Salminen, Saarijarvi, Toikka, Kauhanen, \& Aarela, 2006; Tolmunen et al., 2011), showing significant heritability (Jorgensen, Zachariae, Skytthe, \& Kyvik, 2007), in some cases it may present as a state reaction to severe stress or trauma (Messina, Beadle \& Paradiso, 2014). Further, high levels of alexithymia have been reported in clients diagnosed with various conditions involving emotional dysregulation, including anxiety, depression, and substance use disorders (Gilbert, McEwan, Catarino, Baiao \& Palmeira, 2014; Lyvers, Hinton, Gotsis, Roddy, Edwards, \& Thorberg, 2014; Lyvers, Hanigan \& Thorberg, 2018; Thorberg, Young, Sullivan \& Lyvers, 2009), and evidence for stability has been more mixed in such samples (e.g., de Haan, van der Palen, Wijdeveld, Buitelaar \& De Jong, 2014; Morie, Nich, Hunkele, Potenza \& Carroll, 2015; Thorberg et al., 2016). In a university context, however, Mikolajczak and Luminet (2006) found that alexithymia was stable across time when students were assessed before and after a stressful examination period. Given that resilience requires the ability to effectively self-regulate emotions, alexithymia might be expected to show a negative relationship to resilience. Further, although social support also contributes to resilience (Li, 2008; Williams et al., 2010; Yoon et al., 2014), highly alexithymic individuals may be unlikely to rely on social support as a coping strategy when under stress given their reported interpersonal difficulties (Corbin, Farmer \& NolenHoekesma, 2013; Hamaideh, 2017; Spitzer, Siebel-Jurges, Barnow, Grabe \& Freyberger, 2005); alexithymia has been associated with interpersonal distrust as well as loneliness in social, romantic and familial domains (Qualter, Quinton, Wagner \& Brown, 2009). 
A further issue in the context of university life is the frequent use of alcohol, often in a socializing context but also for stress relief (Borsari, Murphy \& Barnett, 2007; Rickwood et al., 2016; Stewart, Zvolensky \& Eifert, 2002). If excessive, such use can be detrimental to academic achievement, perhaps leading to a worsening of overall stress (Aertgeerts \& Buntinx, 2002; Tembo, Burns \& Kalembo, 2017; Wood, Sher, \& Rutledge, 2007). Recent research summarised by Stafford and Keric (2017) revealed that more than a third of female university students reported drinking at levels defined as hazardous based on their Alcohol Use Disorders Identification Test (AUDIT; Saunders, Aasland, Babor, De La Fuente \& Grant, 1993) scores. Alexithymia has been consistently linked to risky or problematic drinking in university, community and clinical samples (Cruise \& Becerra, 2018; Lyvers, Simons, Hayes \& Thorberg, 2014; Thorberg et al., 2009), as well as the use of alcohol as an avoidant coping strategy to suppress negative affect (Bruce, Curren \& Williams, 2012; Coriale et al., 2012; Corbin et al., 2013; Lyvers, Coundouris, Edwards \& Thorberg, 2018). Alexithymic students are likely to lack sufficient emotional self-regulation and social resources to foster resilience, and thus may be especially vulnerable to university stress and its adverse outcomes such as problematic drinking or persistent anxiety. Like hazardous drinking, anxiety also shows high prevalence among Australian university students compared to the general population (Bitsika, Sharpley \& Peters, 2010), has a positive association with university-related stress (Pidgeon et al., 2014) as well as alexithymia (Lyvers et al., 2018), and is negatively related to resilience (Bacchi \& Licinio, 2017).

Based on the crucial roles of emotion self-regulation skills and social support in fostering resilience, the present study examined resilience in relation to alexithymia, university-related stress, and two common outcomes of stress - problematic drinking and anxiety - in a sample of female university students. Results were expected to support the 
hypothesis that higher levels of resilience would predict lower levels of problematic drinking and anxiety through negative relationships with alexithymia and university stress.

\section{Method}

\section{Participants}

Participants consisted of 136 female university students. Removal of 13 multivariate outliers yielded the final sample of 123 young women, aged 18 to 30 years $(M=21.07$ years, $S D=2.80$ ). Inclusion criteria required participants to be current university students with English-language proficiency and no history of serious head injury or diagnosed psychological disorder. Participants were recruited via emailed announcement at two universities in southeast Queensland and posted on university Facebook pages. Participants were offered the incentive of either entry into a random draw for a $\$ 50$ gift voucher (67 participants; $54 \%$ ) or half a credit point towards a psychology subject (58 participants; $46 \%$ ).

\section{Materials}

The battery of questionnaires was administered to the participants online via the survey platform Qualtrics and was prefaced by an explanatory statement and informed consent page, followed by the instruments reported below.

Demographics. This seven-item self-report questionnaire assessed for age, gender, level of study, English proficiency, absence of previous traumatic brain injury or diagnosed psychological disorder, and current work status.

\section{Resilience Research Centre Adult Resilience Measure (RRC-ARM; Ungar,}

2016). The RRC-ARM is self-report questionnaire consisting of 28 items to which participants respond on a five-point Likert scale ranging from 1 (not at all) to 5 (a lot). The sum of item responses yields a total score that can range from 28 to 140, with higher scores indicating higher levels of resilience. Resilience as assessed by the RRC-ARM encompasses individual capacities (e.g., "I am aware of my own strengths"); personal relationships (e.g., 
"my family know a lot about me"); and sense of belonging (e.g., "I feel I belong in my community”) (Ungar \& Liebenberg, 2011). In the present sample, the internal consistency of the total scale was very high $(\alpha=.93)$.

Toronto Alexithymia Scale (TAS-20; Bagby, Parker et al., 1994). The TAS-20 is a 20-item self-report questionnaire to which participants respond on a five-point Likert scale ranging from 1 (strongly disagree) to 5 (strongly agree). Total scores are calculated by summing all responses and can range from 20 to 100, with higher scores indicating higher levels of alexithymia. Although the present study used the TAS-20 as a continuous measure, established cut-offs (Bagby, Taylor \& Parker, 1994) define scores of 61 or higher as indicative of definite or high alexithymia, whereas scores of 52 to 60 are considered borderline, and scores of 51 or lower indicate low or no significant alexithymia. Seven items measure difficulty identifying feelings (DIF), e.g., "I have feelings that I can't quite identify"; five items measure difficulty describing feelings (DDF), e.g., "it is difficult for me to find the right words for my feelings"; and eight items measure externally oriented thinking (EOT), e.g., "I prefer talking to people about their daily activities rather than their feelings." In the present sample the internal consistency of the total scale was high $(\alpha=.87)$.

University Stress Scale (USS; Stallman \& Hurst, 2016). The USS is a self-report questionnaire consisting of 21 items. Participants respond on a four-point Likert scale ranging from 1 (not at all) to 4 (constantly), with responses scored as 0-3. They are asked to report how often each of the issues described caused them stress in the past month, e.g., "housing/accommodation," "relationship breakdown," "study/life balance.” Item responses are summed to obtain a total score that can range from 0 to 63 , with higher scores suggesting higher levels of university stress. The USS encompasses academic, equity, relationship, practical, parental, and health related stressors. The USS had high internal consistency in the present sample $(\alpha=.84)$. 


\section{Alcohol Use Disorders Identification Test (AUDIT; Saunders, Aasland, Babor,}

De La Fuente \& Grant, 1993). The AUDIT was used to assess participants' levels of problematic drinking. This self-report questionnaire consists of 10 items to which participants respond on a five-point Likert scale ranging from 0 to 4; e.g., the item "how often during the past year have you had a feeling of guilt or remorse after drinking?" has response options ranging from 0 (never) to 4 (4 or more times per week). Items are summed to yield total scores that can range from 0 to 40, with higher scores indicating higher probability of alcohol-related issues. Three factors are represented in the AUDIT: alcohol consumption, alcohol dependence, and alcohol related problems. Given the high levels of alcohol consumption that currently characterize young Australian university students (Rickwood et al., 2016) as well as evidence that social anxiety (common in alexithymia) predicts problematic drinking but not consumption levels in university students (Gilles, Turk \& Fresco, 2007: Lyvers, Hanigan \& Thorberg, 2018), in the current study the items from the alcohol dependence and alcohol related problems subscales were added together to obtain an index of problematic drinking. This index showed high internal consistency $(\alpha=.83)$ in the present sample.

\section{Depression Anxiety and Stress Scales (DASS-21; Lovibond \& Lovibond, 1995).}

The DASS-21 was used to assess anxiety levels of participants. The questionnaire consists of 21 items where respondents are asked to evaluate each statement according to how they felt during the past week on a four-point Likert scale ranging from 0 (did not apply to me at all) to 3 (applied to me very much or most of the time). The DASS-21 consists of three seven-item scales assessing depression, anxiety and stress; for the present study only the Anxiety subscale (e.g., "I felt I was close to panic") was used. Higher scores on this scale indicate higher levels of anxiety. In the present sample, the Anxiety scale showed high internal consistency $(\alpha=.87)$. 


\section{Procedure}

The protocol was approved by the university ethics committee prior to data collection. Participants completed questionnaires anonymously online in uniquely randomized orders. To qualify for their incentive, participants were asked to email a screenshot of the completion page of the online survey to one of the researcher's email address; these were kept until completion of data collection, when the researcher was able to either award credit or enter participants into the draw for the $\$ 50$ gift voucher. The screenshots did not provide any information that could link any participant to their responses.

\section{Results}

In the final sample, 18 of the 123 participants $(15 \%)$ were identified by established TAS-20 cut-off score as definitely or highly alexithymic, which was higher than the reported prevalence of alexithymia of $8 \%$ in a large sample of Finnish women across a broad age range (Mattila, Salminen, Nummi \& Joukamaa, 2006). A further 26 participants (21\%) scored in the "borderline" range. In addition, 49 of the 123 female university students (40\%) had AUDIT scores indicative of hazardous or harmful drinking. Bivariate correlations between study variables are presented in Table 1 . Resilience was significantly negatively correlated with alexithymia, university stress, problematic drinking, and anxiety. Alexithymia was significantly positively correlated with university stress, problematic drinking, and anxiety. University stress was also significantly positively correlated with problematic drinking and anxiety. Problematic drinking was significantly positively correlated with anxiety. All correlations were thus consistent with expectations.

\section{Serial Mediation Overview}

Two serial mediation models were tested via the SPSS macro PROCESS (Model 6; Hayes, 2013) using ordinary least squares path analyses. A bootstrapping procedure of 2000 resamples was implemented to generate bias-corrected $95 \%$ confidence intervals of the 
indirect effects (see Preacher \& Hayes, 2008). The criterion variable of each model was problematic drinking and anxiety, respectively. For both models, resilience was entered as the primary predictor variable, with alexithymia as the first mediator and university stress as the second mediator. A summary of each model is presented in Figure 1 and Figure 2.

\section{Serial Mediation Model Predicting Problematic Drinking}

The first analysis assessed the ability of alexithymia and university stress to serially mediate the relationship between resilience and problematic drinking, while controlling for anxiety. When all variables were entered the model was significant, accounting for approximately $46 \%$ of the variance in problematic drinking, $F(2,120)=48.98, M S E=0.56, p$ $<.001$. Initially, the total effect of resilience predicting problematic drinking was a negative relationship, with higher levels of resilience predicting lower levels of problematic drinking, $\beta=-.18, S E=0.09, p=.050$. Following entry of the mediator variables $(M 1=$ alexithymia, $M 2$ = university stress), resilience did not retain its significant relationship with problematic drinking, $\beta=-.11, S E=0.10, p=.255$. The PROCESS macro evaluates all possible mediation pathways within a model, evaluating both serial and simple variants. Within the current model, two indirect effects were significant as determined by bootstrapped biascorrected $95 \%$ confidence intervals.

The simple mediation of resilience $\rightarrow$ university stress $\rightarrow$ problematic drinking was significant, $\beta=-.04, S E=0.02$, Lower $95 \% \mathrm{CI}=-.097$, Upper $95 \% \mathrm{CI}=-.002$. Specifically, higher levels of resilience predicted less university stress, and less university stress predicted less problematic drinking. The complete serial mediation of resilience $\rightarrow$ alexithymia $\rightarrow$ university stress $\rightarrow$ problematic drinking was also significant, $\beta=-.02, S E=0.01$, Lower 95\% CI $=-.055$, Upper 95\% CI $=-.004$. Specifically, higher levels of resilience predicted lower levels of alexithymia; lower alexithymia predicted less university stress; and finally, less university stress predicted less problematic drinking. That is, after controlling for 
anxiety, the ability of resilience to predict levels of problematic drinking was mediated singularly by university stress, and in a serial pattern including both alexithymia and university stress. The simple mediation of resilience $\rightarrow$ alexithymia $\rightarrow$ problematic drinking was non-significant.

\section{Serial Mediation Model Predicting Anxiety}

The second analysis assessed the ability of alexithymia and university stress to serially mediate the relationship between resilience and self-reported anxiety, while controlling for problematic drinking. When all variables were entered, the model was significant and accounted for approximately $26 \%$ of the variance in anxiety, $F(2,120)=$ 20.55, MSE $=0.76, p<.001$. Higher levels of resilience predicted lower levels of anxiety, $\beta$ $=-.22, S E=0.09, p=.013$. With entry of the mediator variables $(M 1=$ alexithymia,$M 2=$ university stress), the direct effect of resilience and anxiety became non-significant, $\beta=.06$, $S E=0.09, p=.519$. Within the complete model, bootstrapped bias-corrected $95 \%$ confidence intervals indicated that two indirect effects were significant.

The simple mediation of resilience $\rightarrow$ alexithymia $\rightarrow$ anxiety was significant, $\beta=$ $-.22, S E=0.06$, Lower $95 \% \mathrm{CI}=-.350$, Upper $95 \% \mathrm{CI}=-.122$. The results demonstrated that higher levels of resilience predicted lower levels of alexithymia, which in turn predicted lower levels of anxiety. Additionally, the complete serial mediation of resilience $\rightarrow$ alexithymia $\rightarrow$ university stress $\rightarrow$ anxiety was also significant, $\beta=-.03, S E=0.02$, Lower 95\% CI $=-.074$, Upper 95\% CI $=-.009$. Specifically, higher levels of resilience predicted lower levels of alexithymia; lower levels of alexithymia predicted less university stress; and finally, less university stress predicted lower anxiety. Overall, after controlling for problematic drinking, the ability of resilience to predict anxiety was mediated singularly by alexithymia, and in a serial pattern consisting of both alexithymia and university stress. The simple mediation of resilience $\rightarrow$ university stress $\rightarrow$ anxiety was non-significant. 


\section{Discussion}

As expected, higher levels of resilience were associated with lower levels of university stress, which in turn predicted lower levels of problematic drinking. Further, higher levels of resilience were linked to lower levels of alexithymia, which in turn predicted lower anxiety. In the serial mediation models, increased resilience predicted lower levels of both problematic drinking and anxiety through lower levels of alexithymia and, in turn, lower levels of university stress. Present results were thus consistent with the hypothesis that although resilience may protect against problematic drinking and anxiety in university students, it does so through negative associations with alexithymia and university stress. The findings indicate that alexithymic students, presumably lacking the emotional self-regulation skills and social resources that promote resilience, tend to experience higher levels of university-related stress, as well as problematic drinking and anxiety in response to such stress, in comparison to students with low or no alexithymia. This interpretation fits with previous research highlighting the benefits of resilience (Williams et al., 2010), and the serial exacerbation of risk factors that can occur when resilience is low (Kerr et al., 2004; Qualter et al., 2009; Stasiewicz et al., 2012). Additionally, the mediating roles of alexithymia and university stress in the relationship of resilience to problematic drinking were in line with the stress-alexithymia hypothesis. This hypothesis postulates that alexithymic characteristics prevent a person from coping effectively with a stressor due to low emotional self-awareness and poor ability to identify stressful events, combined with the tendency to use action as a primary generalized behavioral response (e.g., engage in risky drinking; Martin \& Pihl, 1985). This interpretation was supported by a recent report that students with alexithymia tended to act more impulsively when experiencing negative affect, promoting increased drinking (Shishido, Gaher \& Simons, 2013). Further, students with alexithymia tend to use alcohol to cope with stress instead of more adaptive coping strategies such as seeking social 
support (Lyvers et al., 2018), presumably due to their persistent interpersonal difficulties (Qualter et al., 2009).

Limitations of the present study include the relatively small sample of female undergraduates and the cross-sectional design. The present study did not include male undergraduates, hence the present findings cannot be generalized to young men at university. Gender differences in alexithymia have sometimes been reported (e.g., Levant, Hall, Williams \& Hassan, 2009; Mason, Tyson, Jones, \& Potts, 2005), as have gender differences in resilience (e.g., Stratta et al., 2013). Future work on these issues should thus include male students in order to improve generalizability and assess for possible gender differences in the observed relationships among variables. The cross-sectional, correlational design of the present study did not allow conclusions to be made concerning temporal relationships among variables and possible causal mechanisms; such issues can only be addressed via suitably designed longitudinal studies, which entail formidable challenges of time, resources, dropout issues, etc. Another limitation of the present study was its use of self-report measures requiring a degree of self-awareness and knowledge about oneself that highly alexithymic individuals may lack. On the other hand, a psychometric comparison study indicated that TAS-20 scores and clinician observer ratings of alexithymia yielded similar results (Thorberg et al., 2010). Finally, although the present sample of young Australian women at university showed a higher prevalence of alexithymia than was reported in the adult female Finnish population across a broad age range (Mattila et al., 2006), this was entirely in line with previous work in young adult Australian samples (e.g., Lyvers et al., 2017).

Taken together, the present findings suggest that students who are low in resilience may lack the protective benefits that come with accurate emotional self-awareness and effective self-regulation skills as well as social resources, especially those with high levels of alexithymia. Resilience training, such as the regimen implemented by Carlson and Voss 
(2017) using positive emotion refocusing and controlled breathing with biofeedback, is one approach that was reportedly helpful to students suffering from anxiety. For those with alexithymia, recent evidence supports the effectiveness of cognitive behavioral therapy (CBT) in reducing alexithymia as well as problematic drinking in a clinical AUD sample (Thorberg et al., 2016). The latter authors noted that significant reduction in TAS-20 alexithymia scores over a 12 week course of treatment was partially mediated by lowered expectancies that alcohol would improve assertiveness and render clients more friendly and outgoing in social situations, leading the authors to suggest that targeting such expectancies in CBT might prove effective in treating alexithymic AUD clients. Promoting resilience of students may not only lead to reductions in university-related stress, but also to reductions in negative outcomes such as anxiety and problematic drinking in the context of the unique combination of stressors encountered at university. 


\section{References}

Aertgeerts, B., \& Buntinx, F. (2002). The relation between alcohol abuse or dependence and academic performance in first-year college students. Journal of Adolescent Health, 31, 223-225. doi:10.1016/S1054-139X(02)00362-2

Australian Psychological Society (2015). Stress and wellbeing: How Australians are coping with life. Retrieved from https://www.psychology.org.au/Assets/Files/PW15-SR.pdf

Bacchi, S., \& Licinio, J. (2017). Resilience and psychological distress in psychology and medical students. Academic Psychiatry, 41, 185-188. doi:10.1007/s40596-016-0488-0

Bagby, R. M., Parker, J. D. A., \& Taylor, G. J. (1994). The twenty-item Alexithymia scale-I. Item selection and cross-validation of the factor structure. Journal of Psychosomatic Research, 38, 23-32. doi:10.1016/0022-39999(94)90005-1

Bagby, R. M., Taylor, G. J., \& Parker, J. D. (1994). The twenty-item Alexithymia scale-II. Convergent, discriminant and concurrent validity. Journal of Psychosomatic Research, 38, 33-40. doi:10.1016/0022-39999(94)90006-X

Bitsika, V., Sharpley, C. F., \& Peters, K. (2010b). How is resilience associated with anxiety and depression? Analysis of factor score interactions within a homogenous sample. German Journal of Psychiatry, 13, 9-16.

Borsari, B., Murphy, J. G., \& Barnett, N. P. (2007). Predictors of alcohol use during the first year of college: Implications for prevention. Addictive Behaviors, 32, 2062-2086. doi:10.16/j.addbeh.2007.01.017

Bruce, G., Curren, C., \& Williams, L. (2012). Alexithymia and alcohol consumption: The mediating effects of drinking motives. Addictive Behaviors, 37, 350-352. doi:10.1016/j.addbeh.2011.11.024

Carlson, E., \& Voss, J. (2017). Using personal resilience techniques to reduce anxiety in university students. Western Journal of Nursing Research, 39, 1368. 
doi:10.1177/0193945917715261d

Gilbert., P., McEwan., K., Catarino., F., Baiao., R \& Palmeira., L. (2014). Fears of happiness and compassion in relationship with depression, alexithymia, and attachment security in a depressed sample. British Journal of Clinical Psychology, 53, 228-244. doi:

10.1111/bjc. 12037

Gilles, D. M., Turk, C. L., \& Fresco, D. M. (2006). Social anxiety, alcohol expectancies, and self-efficacy as predictors of heavy drinking in college students. Addictive Behaviors, 31, 388-398. doi:10.1016/j.addbeh.2005.05.020

Corbin, W. R., Farmer, N. M., \& Nolen-Hoekesma, S. (2013). Relations among stress, coping strategies, alcohol consumption and related problems: A mediated moderation model. Addictive Behaviors, 38, 1912-1919. doi:10.1016/j.addbeh.2012.12.005

Coriale, G., Bilotta, E., Leone, L., Cosimi, F., Porrari, R., De Rosa, F., \& Ceccanti, M. (2012). Avoidance coping strategies, alexithymia and alcohol abuse: A mediation analysis. Addictive Behaviors, 37, 1224-1229. doi:10.1016/j.addbeh.2012.05.018

Cruise, K.E., \& Becerra, R. (2018). Alexithymia and problematic alcohol use: A critical review. Addictive Behaviors, 77, 232-246. doi: 10.106/addbeh.2017.09.025

de Haan, H.A., van der Palen, J., Wijdeveld, T.G., Buitelaar, J.K., \& De Jong, C.A. (2014). Alexithymia in patients with substance use disorders: State or trait? Psychiatry Research, 216, 137-145. doi: 10.1016/j.psychres.2013.12.047.

Gilles, D. M., Turk, C. L., \& Fresco, D. M. (2006). Social anxiety, alcohol expectancies, and self-efficacy as predictors of heavy drinking in college students. Addictive Behaviors, 31, 388-398. doi:10.1016/j.addbeh.2005.05.020

Hamaideh, S. H. (2017). Alexithymia among Jordanian university students: Its prevalence and correlates with depression, anxiety, stress, and demographics. Perspectives in Psychiatric Care, 54, 274-280. doi:10.1111/ppc.12234 
Hartley, M. T. (2011). Examining the relationships between resilience, mental health, and academic persistence in undergraduate college students. Journal of American College Health, 59, 596-604. doi:10.1080/07448481.2010.515632

Hayes, A.F. (2013). Introduction to mediation, moderation, and conditional process analysis: A regression-based approach. New York, NY: Guilford Press.

Hiirola, A., Pirkola, S., Karukivi, M., Markkula, N., Bagby, R.M., Joukamaa, M., Jula, A., Kronholm, E., Saarijärvi, S., Salminen, J.K., Suvisaari, J., Taylor, G., \& Mattila, A.K. (2017). An evaluation of the absolute and relative stability of alexithymia over 11 years in a Finnish general population. Journal of Psychosomatic Research, 95, 81-87. doi: 10.1016/j.jpsychores.2017.02.007.

Jorgensen, M. M., Zachariae, R., Skytthe, A., \& Kyvik, K. (2007). Genetic and environmental factors in alexithymia: A population based study of 8785 Danish twin pairs. Psychotherapy \& Psychosomatics, 76, 369-375. doi:10.1159/000107565

Kerr, S., Johnson, V. K., Gans, S. E., \& Krumrine, J. (2004). Predicting adjustment during the transition to college: Alexithymia, perceived stress and psychological symptoms. Journal of College Student Development, 45, 593-611. doi:10.1353/csd.2004.0068

Li, M. H. (2008). Relationships among stress coping, secure attachment and the trait of resilience among Taiwanese college students. College Student Journal, 42, 312-325.

Levant, R. F., Hall, R. J., Williams, C. M., \& Hasan, N. T. (2009). Gender differences in alexithymia. Psychology of Men \& Masculinity, 10, 190-203. http://dx.doi.org/10.1037/a0015652

Lovibond, P. F., \& Lovibond, S. H. (1995). The structure of negative emotional states: Comparison of the Depression Anxiety Stress Scales (DASS) and the Beck Depression and Anxiety Inventories. Behavior Research \& Therapy, 33, 335-343.

doi:10.1016/0005-7967(94)00075-U 
Lyvers, M., Coundouris, S., Edwards, M.S., \& Thorberg, F.A. (2018). Personality, drinking motives and risky alcohol use: The role of internal drinking motives. Addiction Research \& Theory, 26, 114-122. doi: 10.1080/16066359.2017.1333110

Lyvers, M., Hanigan, C., \& Thorberg, F.A. (2018). Social interaction anxiety, alexithymia, and drinking motives in Australian university students. Journal of Psychoactive Drugs, 50, 402-410. doi: 10.1080/02791072.2018.1517228

Lyvers, M., Kohlsdorf, S.M., Edwards, M.S., \& Thorberg, F.A. (2017). Alexithymia and mood: Recognition of emotion in self and others. American Journal of Psychology, 130, 83-92. doi: 10.5406/amerjpsyc.130.1.0083

Lyvers, M., Hinton, R., Gotsis, S., Roddy, M., Edwards, M. S., \& Thorberg, F.A. (2014). Traits linked to executive and reward systems functioning in clients undergoing residential treatment for substance dependence. Personality \& Individual Differences, 70, 194-199. doi: 10.1016/j.paid.2014.07.004

Lyvers, M., Simons, O., Hayes, A., \& Thornberg, F. A. (2014). Drinking motives, alcohol expectancies and alexithymia in social drinkers. Journal of Substance Use, 19, 44-47. doi:10.3109/14659891.2012.734538

Martin, J. B., \& Pihl, R. O. (1985). The stress-alexithymia hypothesis: Theoretical and empirical considerations. Psychotherapy and Psychosomatics 43, 169-176. doi: $10.1159 / 000287876$

Mason, O., Tyson, M., Jones, C., \& Potts, S. (2010). Alexithymia: Its prevalence and correlates in a British undergraduate sample. Psychology \& Psychotherapy, 78, 113125. doi: 10.1348/147608304X21374

Mattila, A. K., Salminen, J. K., Nummi, T., \& Joukamaa, M. (2006). Age is strongly associated with alexithymia in the general population. Journal of Psychosomatic Research, 61, 629-663. doi:10.1016/j.jpsychores.2006.04.013 
Messina, A., Beadle, J. N., \& Paradiso, S. (2014). Towards a classification of alexithymia: Primary, secondary and organic. Journal of Psychopathology, 20, 38-49.

Mikolajczak, M., \& Luminet, O. (2006). Is alexithymia affected by situational stress or is it a stable trait related to emotion regulation? Personality \& Individual Differences, 40, 1399-1408. doi:10.1016/j.paid/2005.10.020

Morie, K.P., Nich, C., Hunkele, K., Potenza, M.N., \& Carroll, K.M. (2015). Alexithymia level and response to computer-based training in cognitive behavioral therapy among cocaine-dependent methadone maintained individuals. Drug and Alcohol Dependence, 152, 157-163. doi: 10.1016/j.drugalcdep.2015.04.004

Pidgeon, A. M., McGrath, S., Magya, H. B., Stapleton, P., \& Lo, B. C. Y. (2014). Psychosocial moderators of perceived stress, anxiety, and depression in university students: An international study. Open Journal of Social Sciences, 2, 23-31. doi:10.4236/jss.2014.211004

Pidgeon, A. M., Rowe, N. F., Stapleton, P., Magyar, H. B., \& Lo, B. C. Y. (2014). Examining characteristics of resilience among university students: An international study. Open Journal of Social Sciences, 2, 14-22. doi:10.4236/jss.2014.211003

Preacher, K.J., \& Hayes, A. F. (2008). Asymptotic and resampling strategies for assessing and comparing indirect effects in multiple mediator models. Behavior Research Methods, 40, 879-891. doi: 10.3758/BRM.40.3.879

Qualter, P., Quinton., S. J., Wagner., H., \& Brown., S. (2009). Loneliness, interpersonal distrust, and alexithymia in university students. Journal of Applied Social Psychology, 39, 1461-1479. doi: 10.1111/j.1559-1816.2009.00491.x

Rickwood, D., Telford, N., O’Sullivan, S., Crisp, D., \& Magyar, R. (2016). Headspace: National tertiary student wellbeing survey 2016. Retrieved from https://headspace.org.au/assets/Uploads/headspace-NUS-Publication-Digital.pdf 
Salminen, J. K., Saarijarvi, S., Toikka, T., Kauhanen, J., Aarela, E. (2006). Alexithymia behaves as a personality trait over a 5-year period in Finnish general population. Journal of Psychosomatic Research, 61, 275-278. doi:10.1016/jpsychores.2006.01.014

Saunders, J. B., Aasland, O. G., Babor, T. F., De La Fuente, J. R., \& Grant, M. (1993). Development of the alcohol use disorder identification test (AUDIT): WHO collaborative project on early detection of person with harmful alcohol consumption-II. Addiction, 88, 791-804. doi:10.1111/j.1360-0443.1993.tb02093.x

Shi, M., Liu, L., Wang, Z. Y., \& Wang, L. (2015). Mediating role of resilience in the relationship between big five personality and anxiety among Chinese medical students: A cross sectional study. PLoS ONE, 10, 1-12. doi: 10.1371/journal.pone.0119916

Shishido, H., Gaher, R. M., \& Simons, J. S. (2013). I don't know how I feel, therefore I act: Alexithymia, urgency, and alcohol problems. Addictive Behaviors, 38, 2014-2017. doi: 10.1016/j.addbeh.2012.12.014

Sifneos, P. E. (1973). The prevalence of 'alexithymic' characteristics in psychosomatic patients. Psychotherapy and Psychosomatics, 22, 255-262. doi: 10.1159/000286529

Spitzer, C., Siebel-Jurges, U., Barnow, S., Grabe, H. J., \& Freyberger, H. J. (2005). Alexithymia and interpersonal problems. Psychotherapy \& Psychosomatics, 74, 240206. doi: $10.1159 / 000085148$

Stafford, J., \& Keric, D. (2017). Alcohol in the university setting: A resource to support Australian universities. Perth: McCusker Centre for Action on Alcohol and Youth, Curtin University.

Stasiewicz, P. R., Bradizza, C. M., Gudleski, G. D., Coffey, S. F., Schlauch, R. C., Bailey, S. T., Bole, C. W., \& Gulliver, S. B. (2012). The relationship of alexithymia to emotional dysregulation within an alcohol dependent treatment sample. Addictive Behaviors, 37, 469-476. doi: 10.1016/j.addbeh.2011.12.011 
Stallman, H. M., \& Hurst, C. P. (2016). The University Stress Scale: Measuring domains and extent of stress in university students. Australian Psychologist, 51, 128-134. doi:10.1111/ap.12127

Stewart, S. H., Zvolensky, M. J., \& Eifert, G. H. (2002). The relations of anxiety sensitivity, experiential avoidance, and alexithymic coping to young adults' motivations for drinking. Behavior Modification, 26, 274-296. doi:10.1177/045445502026002007

Stratta, P., Capannac, C., Patriarcac, S., de Cataldo, S., Bonannia, R. L., Riccardic, I., \& Rossic, A. (2013). Resilience in adolescence: Gender differences two years after the earthquake of L'Aquila. Personality \& Individual Differences, 54, 327-331. doi: 10.1016/j.paid.2012.09.016

Taylor., G. J., \& Bagby., R. M. (2004). New trends in alexithymia research. Psychotherapy and Psychosomatics, 73, 68-77. doi: 10.1159/000075537

Tembo, C., Burns, S., \& Kalembo, F. (2017). The association between levels of alcohol consumption and mental health problems and academic performance among young university students. PLoS ONE, 12, 1-13. doi:10.1371/journal.pone.0178142

Thorberg, F. A., Young, R. McD., Sullivan, K. A., Lyvers, M., Hurst, C., Tyssen, R.,...., \& Feeney, G. F. X. (2016). A longitudinal mediational study on the stability of alexithymia among alcohol-dependent outpatients in Cognitive-Behavioral Therapy. Psychology of Addictive Behaviors, 30, 64-72. doi: 10.1037/adb0000135

Thorberg, F. A., Young, R. M., Sullivan, K. A., \& Lyvers, M. (2009). Alexithymia and alcohol use disorders: A critical review. Addictive Behaviors, 34, 237-245. doi:10.1016/j.addbeh.2008.10.016

Thorberg, F. A., Young, R. McD., Sullivan, K. A., Lyvers, M., Connor, J. P., \& Feeney, G. F. X. (2010). A psychometric comparison of the Toronto Alexithymia Scale (TAS-20) and 
the Observer Alexithymia Scale (OAS) in an alcohol dependent sample. Personality \& Individual Differences, 49, 119-123. doi: 10.1016/j.paid.2010.03.018

Thorberg, F. A., Young, R. M., Sullivan, K. A., \& Lyvers, M. (2011). Parental bonding and alexithymia: A meta-analysis. European Psychiatry, 26, 187-193. doi:

10.1016/j.eurpsy.2010.09.010

Tolmunen, T., Heliste, M., Lehto, S.M., Hintikka, J., Honkalampi, K., \& Kauhanen, J. (2011). Stability of alexithymia in the general population: An 11-year follow-up. Comprehensive Psychiatry, 52, 536-41. doi: 10.1016/j.comppsych.2010.09.007.

Ungar, M. (2016). The Resilience Research Centre Adult Resilience Measure (RRC-ARM). Retrieved from: http://resilienceresearch.org

Ungar, M., \& Liebenberg, L. (2011). Assessing resilience across cultures using mixed methods: Construction of the child and youth resilience measure. Journal of Mixed Methods Research, 5, 126-149. doi:10.1177/155868981140607

Williams, V., Ciarrochi, J., \& Deane, F. P. (2010). On being mindful, emotionally aware, and more resilient: Longitudinal pilot study of police recruits. Australian Psychologist, 45, 274-282. doi:10.1080/00050060903573197

Wood, P. K., Sher, K. J., \& Rutledge, P. C. (2007). College student alcohol consumption, day of the week, and class schedule. Alcoholism: Clinical \& Experimental Research, 31, 1195-1207. doi:10.1111/j.1530-0277.2007.00402.x

Yoon, J. H., Lee, J. H., Lee, C. Y., Cho, M., \& Lee, S. M. (2014). Suppressor effects of coping strategies on resilience. Asia Pacific Education Review, 15, 537-545. doi:10.1007/s12564-014-9343-8 
Table 1

Intercorrelations, means, and standard deviations of study variables

\begin{tabular}{lcccccc}
\hline Variable & 1 & 2 & 3 & 4 & $M$ & $S D$ \\
\hline 1. Resilience & --- & & & & 111.46 & 14.81 \\
2. University Stress & $-.35^{* * *}$ & --- & & & 39.15 & 7.12 \\
3. Alexithymia & $-.49^{* * *}$ & $.46^{* * *}$ & --- & & 47.30 & 11.34 \\
4. Problem Drinking & $-.24^{* *}$ & $.34^{* * *}$ & $.25^{* *}$ & --- & 2.34 & 3.00 \\
& & & & & & \\
5. Anxiety & $-.27^{* * *}$ & $.43^{* * *}$ & $.58^{* * *}$ & $.26 * *$ & 11.96 & 4.73 \\
& & & & & & \\
\hline
\end{tabular}

$* * p<.01 . * * * p<.001$ 


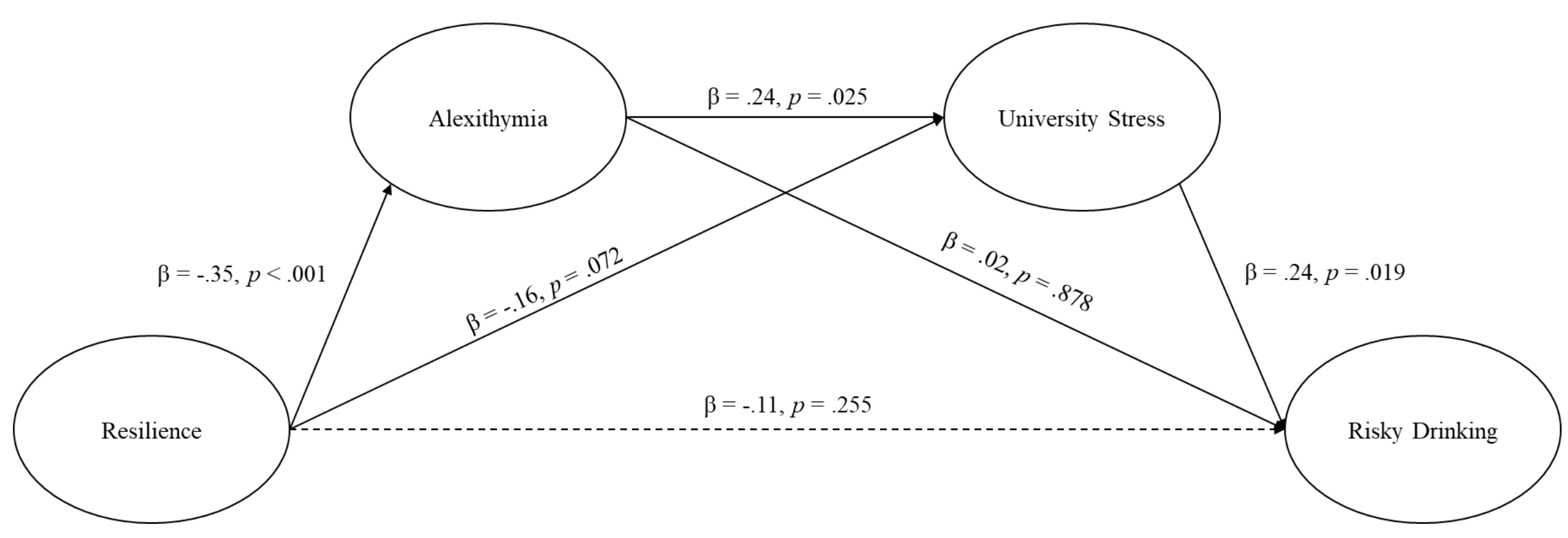

Figure 1. Standardized coefficients and significance of individual pathways within the serial mediation model depicting the predictive relationship of resilience and problematic drinking as mediated by alexithymia and university stress while controlling for anxiety. 


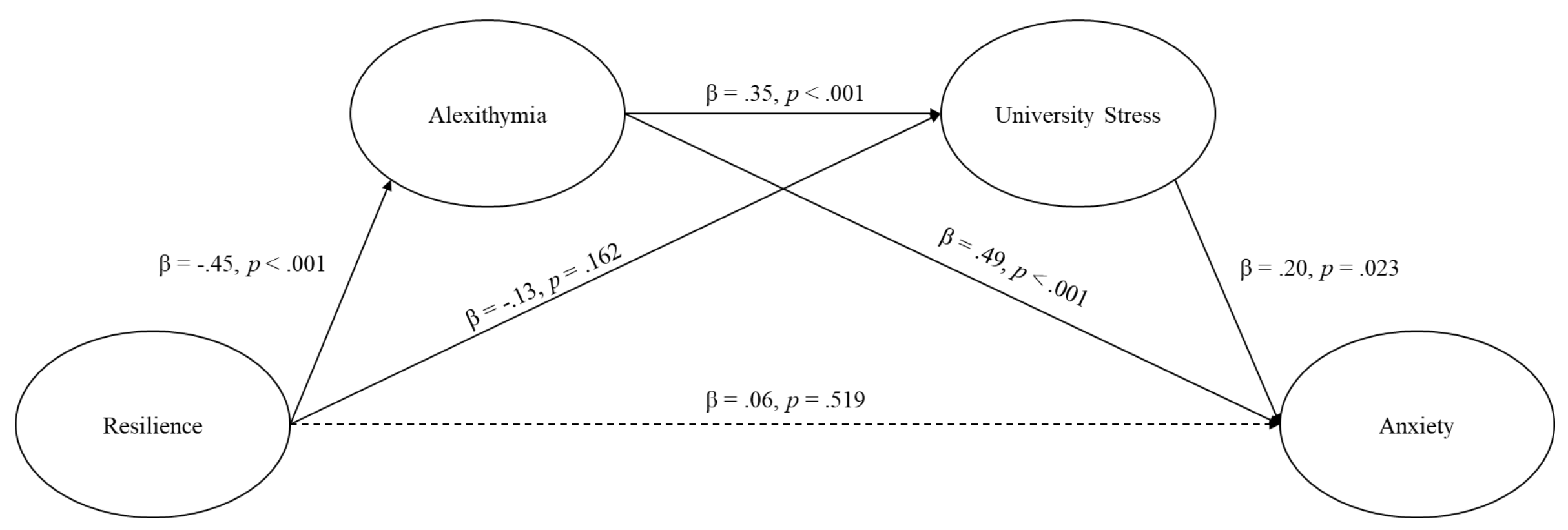

Figure 2. Standardized coefficients and significance of individual pathways within the serial mediation model depicting the predictive

relationship of resilience and anxiety as mediated by alexithymia and university stress while controlling for problematic drinking. 